\title{
LA II REPÚBLICA Y LA GUERRA CIVIL DESDE LA PERSPECTIVA ACTUAL
}

Durante los días 17 a 21 de Julio de 2006 se celebró en Alicante el curso titulado La II República y la Guerra Civil desde la perspectiva actual, dentro del marco de los Cursos de Verano Rafael Altamira, organizados por el Vicerrectorado de Extensión Universitaria de la Universidad de Alicante. Dirigidas por el catedrático de historia contemporánea Glicerio Sánchez Recio, el objetivo de las jornadas fue el analizar y debatir el significado histórico de aquellos dos importantes fenómenos que marcaron para siempre el acontecer histórico y social de nuestro país, desde una perspectiva actual, centrándose especialmente en aquellos aspectos que más preocupan a la opinión pública de hoy en día. Además servía para recordar la doble efeméride del 75 aniversario de la proclamación de la II República y del 70 del comienzo de la Guerra Civil.

La primera intervención, que supuso la apertura del curso, fue la del conocido periodista y comentarista político Eduardo Sotillos Palet, quien demostró con varios ejemplos la vigencia de estos acontecimientos en la prensa actual. Su conferencia, titulada La II República y la guerra en el debate político actual, derivó hacia un análisis de la polarización hacia la derecha que había sufrido el tema, y la necesidad de una reintegración completa a todos los efectos de los perdedores y una reacción eficaz de la izquierda. En la sesión de tarde, el profesor Pedro Payá López, de la Universidad de Alicante, hizo un interesantísimo recorrido tanto en palabras como en imágenes acerca de la representación de la Guerra Civil en el cine español. Con el título de Imágenes de una guerra, la conferencia-proyección se estructuró en tres bloques definidos que partían del primer cine de propaganda franquista, comparando por el camino los puntos de vista de uno y otro bando, y terminando con el actual intento de recuperación de la memoria, ejemplificado en el film de David Trueba Soldados de Salamina.

El segundo día de las jornadas comenzó con la conferencia El consenso en la implantación de los regímenes democráticos: desde el de 1931 al de 1978, del profesor Glicerio Sánchez Recio, de la Universidad de Alicante, en la que proponía un seguimiento y comparación del tratamiento de los hechos entre la II República, la Transición Democráti- 
ca y la actualidad, a través de la prensa. Este esquema le sirvió para demostrar ciertas coincidencias históricas que se repiten a lo largo del tiempo a la hora de abordar algunos temas.

A continuación, el curso contó con la presencia del ex Secretario de Estado de Universidades e Investigación, Salvador Ordóñez Delgado, quien presentó una conferencia titulada $E l$ laicismo republicano y las reformas educativas actuales. En ella planteó una panorámica general acerca de la trayectoria del laicismo en la educación española desde la II República, para concluir con una reflexión sobre la situación de la educación actual y el papel preponderante que el laicismo debe jugar en ella.

Posteriormente, y como colofón a la segunda jornada, el profesor Gabriel Cardona Escanero, de la Universidad de Barcelona, ofreció a los asistentes una visión de los hechos desde el punto de vista militar. Su intervención $L a$ reforma militar de Azaña y las reformas de Narcís Serra, se convirtió en una reflexión crítica acerca del papel del ejército en la reciente historia española, estableciendo un flexible margen cronológico que abarcaba desde la II República hasta los primeros gobiernos socialistas.

La sesión del día 19 comenzó con la presencia del profesor Francisco Sevillano Calero, de la Universidad de Alicante, quien, con su conferencia $E l$ revisionismo historiográfico sobre el pasado reciente de España, planteó una panorámica general sobre el revisionismo en nuestro país, centrándose en el análisis de la figura de Pío Moa y el impacto de su libro Los mitos de la Guerra Civil, abogando como conclusión en la necesidad de diferenciar el pasado y la historia, la instrumentalización social del primero de su conocimiento objetivo, que lleve a los historiadores a un responsable "uso público de la historia" en la construcción de la identidad y la memoria sociales.

Cerraría la sesión la profesora Mónica Moreno Seco, de la Universidad de Alicante, con una reflexión sobre El recuerdo actual del papel de las mujeres en el periodo republicano y la Guerra Civil. En ella analizó, desde una panorámica de género, algunas cuestiones tradicionalmente olvidadas por la historiografía, así como los diferentes roles que desempeñó la mujer durante la República y la Guerra, desde las milicianas a las amas de casa, pasando por la importancia de las mujeres de la retaguardia.

El cuarto día de curso lo abrió el teólogo Juan José Tamayo Acosta, de la Universidad Carlos III de Madrid, con una intervención titulada La posición de la jerarquía eclesiástica actual ante la experiencia política y religiosa de la II República y la Guerra Civil. Lo que en ella se planteó fue una reflexión crítica sobre el punto de vista de la Iglesia, comparando ciertas actitudes dadas durante la República, la Guerra e incluso la Transición, y sus posiciones actuales.

Seguidamente, tomó la palabra el profesor Julio Aróstegui Sánchez, de la Universidad Complutense de Madrid, para analizar La doble cara de la represión desde la perspectiva actual. En su intervención, y tras una serie de precisiones conceptuales, reflexionó sobre la variedad de puntos de vista que encierra el estudio de la represión en la actualidad.

La quinta y última sesión comenzó con la intervención del profesor Fran- 
cisco Espinosa Maestre, de la Universidad de Sevilla, quien, bajo el título de La represión en la Segunda División Orgánica: la columna de la muerte, analizó las dificultades que entraña el estudio de la represión por, entre otras razones, la dificultad en la interpretación de las fuentes. Como ejemplo reflexionó acerca de la investigación desde una fotografía de la represión en Extremadura usada por los dos bandos y ubicaba en distintos lugares de la geografía española.

A continuación la palabra fue para el profesor Julián Chaves Palacios, de la Universidad de Extremadura, quien profundizó en el tema de la represión, sus dificultades y las diferentes interpretaciones de un mismo hecho. Todo ello centrado, según indicaba el título de su conferencia, en La represión en Badajoz.

Tras ellos, y como colofón a la sesión y al curso, se abrió una mesa redonda a la que se sumaron Francisco Moreno Sáez, miembro de la Asocia- ción Cívica para la Recuperación de la Memoria Histórica de Alicante, y el profesor Miguel Ors Montenegro, profesor de la Universidad Cardenal Herrera-CEU de Elche y de la Universidad de Alicante. En ella se abordó en profundidad la cuestión de la memoria histórica, de su importancia y su estado actual. De las numerosas intervenciones, quizás destacó aquella en la que el profesor Julio Aróstegui abogaba por la necesidad de un cambio de estrategia, que no pasaba tanto por cambiar nombres de calles y plazas, como por entrar en las aulas y reflexionar abierta y profundamente sobre la cuestión. De esta manera el desconocimiento existente en la juventud, así como la influencia negativa que ha supuesto el revisionismo más reciente, se convirtieron en el tema central del debate con el que se cerraron las jornadas.

Carlos Aragüez Rubio Universidad de Alicante 